\title{
Overexpression and hyperphosphorylation of retinoblastoma protein in the progression of malignant melanoma
}

\author{
Alexander Roesch ${ }^{1}$, Bernd Becker ${ }^{1}$, Stefanie Meyer ${ }^{1}$, Christian Hafner ${ }^{1}$, Peter Johannes \\ Wild $^{2}$, Michael Landthaler ${ }^{1}$ and Thomas Vogt $^{1}$ \\ ${ }^{1}$ Department of Dermatology, University of Regensburg, Regensburg, Germany and ${ }^{2}$ Institute of Pathology, \\ University of Regensburg, Regensburg, Germany
}

\begin{abstract}
Mutation, absence or abnormal functioning of retinoblastoma protein are fundamental elements of uncontrolled growth in human cancer. In this study, we analyze the expression of retinoblastoma protein and phosphorylated retinoblastoma protein in melanocytic tumors in vivo. Real-time RT-PCR and immunohistochemistry (tissue microarrays and conventional histological sections) reveal that retinoblastoma protein is progressively upregulated in advanced and metastatic malignant melanomas in vivo. However, this increase is paralleled by increased retinoblastoma protein inactivation due to protein phosphorylation. Interestingly, retinoblastoma protein phosphorylation occurs not homogeneously, but with a 'growth zone'-related pattern. In superficial spreading melanomas a subepidermal-lateral maximum of phosphorylated retinoblastoma protein can be frequently observed. Accordingly, nodular vertically invasive melanomas are characterized by a strong staining of phosphorylated retinoblastoma protein in deep-dermal invading protrusions of the tumor. Furthermore, Kaplan-Meier analysis of 13 cases of advanced melanomas with long-time follow-up suggests a significant negative impact of retinoblastoma protein phosphorylation on survival of melanoma patients independent of tumor thickness. We conclude that the evaluation of phosphorylated retinoblastoma protein in melanocytic tumors could become a helpful adjunct in clinicopathological routine.

Modern Pathology (2005) 18, 565-572, advance online publication, 22 October 2004; doi:10.1038/modpathol.3800324
\end{abstract}

Keywords: cell cycle; immunohistochemistry; malignant melanoma; retinoblastoma protein; tumor progression; tumor suppressor gene

The main principle of cell cycle homeostasis is the phosphorylation-dependent activation and deactivation of regulatory proteins upstream of retinoblastoma protein $(\mathrm{pRb})$, which represents the central cycle-controlling element. At the G1/S transition, the antiproliferative function of active, hypophosphorylated $\mathrm{pRb}$ is mediated by its binding capacity to proproliferative transcription factors such as E2F, c-Myc, ATF-2 and c-Abl. ${ }^{1}$ Surprisingly, with the exception of retinoblastoma, osteosarcoma and small cell lung carcinoma, the overall rate of $\mathrm{pRb}$ mutations in the vast majority of human cancers is either extremely low or not existent. ${ }^{2}$ Also in malignant melanomas, the loss of cell cycle control is thought to be due to a lack of pRb activity and not

Correspondence: Dr A Roesch, MD, Department of Dermatology, University of Regensburg, Franz-Josef Strauss-Allee 11, D-93053 Regensburg, Germany.

E-mail: alexander.roesch@klinik.uni-regensburg.de

Received 3 August 2004; revised and accepted 21 September 2004; published online 22 October 2004 to lack of expression or mutation. ${ }^{3,4}$ Currently, the concept is arguably accepted that persistent inactivation and hyperphosphorylation of wild-type $\mathrm{pRb}$ in melanomas is caused by a sustained cyclindependent kinase (cdk) activity. ${ }^{5-7}$ In uveal malignant melanomas, Brantley et $a l^{8,9}$ have recently reported an increased pRb phosphorylation at Ser807/811. Since they have also detected a high cyclin D expression, the hypothesis of a functional inactivation of pRb due to cyclin- and cdk-dependent hyperphosphorylation was further substantiated.

To the best of our knowledge, no detailed studies have been performed to elucidate the pRb phosphorylation status in in vivo samples of cutaneous melanocytic tumors. In particular, studies on the impact of hyperphosphorylated $\mathrm{pRb}$ on melanoma progression are still lacking. Therefore, in this study we analyze total pRb and phosphorylated $\mathrm{pRb}$ expression in tumor biopsies of progressive and nonprogressive melanocytic lesions including common and dysplastic nevi, primary melanomas, 
melanoma metastases and, as control, further neuroectodermal tumors such as glioblastomas, schwannomas and neurofibromas. To disclose a potential association of the histologically detectable degree of $\mathrm{pRb}$ phosphorylation and the prognosis of melanoma patients, a panel of long-term survivors with thick, high-risk primary melanomas (TD $>3.5 \mathrm{~mm}$ ) were analyzed with Kaplan-Meier statistics.

\section{Materials and methods}

\section{Tissue Samples and RNA Sources}

Fresh, uncultured tumor materials of six melanocytic nevi, five primary malignant melanomas and seven melanoma metastases (lymph nodes and cutaneous metastases) were collected. Samples of five glioblastomas were a kind gift from Juergen Schlegel, Department of Neuropathology, TU Munich, Germany. Detailed tumor data of the melanocytic samples and the technical details of microdissection and RNA extraction have been recently published. ${ }^{10}$ Control RNAs from nonmelanocytic tissues were obtained from Ambion Inc., Austin/TX, USA and BD Biosciences, Heidelberg, Germany.

\section{Gene Expression Analysis}

RT-PCR was performed using the Reverse Transcription $\mathrm{Kit}^{\mathrm{TM}}$ (Promega, MD, USA) according to the recommended protocol. For relative quantitation of transcribed gene-specific RNA, TaqMan ${ }^{\mathrm{TM}}$ real-time RT-PCR (Applied Biosystems, Darmstadt, Germany) was performed as described. ${ }^{11,12}$ Primers and probe for Rb-mRNA detection were purchased from Applied Biosystems (Assay on demand ${ }^{\mathrm{TM}}$, Applied Biosystems, Darmstadt, Germany). Primers and probe for 18s rRNA served as endogenous controls using the corresponding predesigned assay (also Applied Biosystems). For each sample, triplicate reactions were performed. Relative expression ratios were calculated using a standard curve generated with Human Reference RNA (Stratagene, La Jolla, USA), which contains pooled RNAs from 11 different tumor cell lines. ${ }^{10}$

\section{Tissue Microarrays}

According to the method established by Kononen et $a l^{13}$ two tissue microarrays were designed in cooperation with the Institute of Pathology, University of Regensburg, Germany. Tissue microarray 'No. 1' represents formalin-fixed paraffinembedded punches from 60 melanoma metastases, tissue microarray 'No. 2' samples from 60 common melanocytic nevi. All tissue samples and clinical information are archived at the Department of Dermatology and the Institute of Pathology, University of Regensburg.

\section{Immunohistochemistry}

Tissue microarrays and conventional paraffinembedded tissue sections were prepared according to standard protocols and subsequently incubated with a 1:100 dilution of the primary antibody for 30 min at room temperature. For total pRb detection, Rb (4H1) Monoclonal antibody was obtained from Cell Signaling Technology/New England Biolabs GmbH, Frankfurt, Germany. For detection of phosphorylated $\mathrm{pRb}$, we used Phospho-Rb (Ser795), Phospho-Rb (Ser780) and Phospho-Rb (Ser807/811) antibodies from the same manufacturer. To avoid experimental bias within the set of tumor samples, immunohistochemistry of all examined tissue samples was performed under identical experimental conditions.

\section{Immunohistochemical Evaluation of Total $p R b$ and Phosphorylated pRb (p-pRb) Expression Using Tissue Microarrays}

Tissue microarrays were examined to proof gross constitutive differences in pRb- and p-pRb-expression between 'full scale' malignant melanocytic tumors (metastases) and benign. To reduce bias, immunostaining was assessed by two independent investigators in a blinded fashion. Inter- and intraexaminer reproducibility was 92 and $95 \%$, respectively. Immunostaining intensity was scored using uniform and clear cutoff criteria to maintain the reproducibility of the method. Briefly, the result of immunostaining was recorded as negative or positive considering the expression in tumor cells. In case of total pRb, p-pRb Ser780 and p-pRb Ser795, samples were classified as positive if more than $10 \%$ of the tumor cells achieved higher signals than the internal positive controls (stratum germinativum of the epidermis). Since p-pRb Ser807/811-staining appeared comparably low, the threshold was set to $5 \%$ positively stained tumor cells.

\section{Immunohistochemical Evaluation of Total $p R b$ and Relative p-pRb Expression in 'Whole Tumor'-Tissue Sections}

Since the punched samples arrayed on the tissue microarrays may fail to represent possible heterogeneity of $\mathrm{pRb} / \mathrm{p}-\mathrm{pRb}$ expression, complete tumor sections (five papillomatous nevi, four dysplastic nevi, five superficial spreading melanomas, 20 nodular melanomas, five melanoma metastases, five neurofibromas, five schwannomas) were analyzed in a second set of experiments. As it became apparent that the number of stained nuclei and the staining intensity can vary grossly within one tumor, a more complex evaluation algorithm was applied for complete sections. For each sample, three representative fields of vision were evaluated at $\times 400$ magnification in (a) a region with maximum and (b) a region with minimum staining, respectively. The number of 
positive-stained nuclei was estimated as percentage of all nuclei $(p)$. In addition, the staining intensities (i) of positive cells were scaled. Cells showing a slight granular staining pattern were graded as 1 , whereas cells with completely filled nuclei were graded as 4 . Grades 2 and 3 were assigned to intermediate staining intensities. Based on mean staining percentages $(p)$ and intensities $(i)$ of all samples $(n)$ of a given pathologically determined entity expression scores (ES) were calculated for both the regions with maximum and the regions with minimum expression according to the following formula:

$$
\begin{aligned}
& \mathrm{ES}_{\max }=\frac{\left(\overline{p_{n 1}}+\overline{p_{n 2}}+\cdots \overline{p_{n x}}\right)}{n} \times \frac{\left(\overline{i_{n 1}}+\overline{i_{n 2}}+\cdots \overline{i_{n x}}\right)}{n} \\
& \mathrm{ES}_{\min }=\frac{\left(\overline{p_{n 1}}+\overline{p_{n 2}}+\cdots \overline{p_{n x}}\right)}{n} \times \frac{\left(\overline{i_{n 1}}+\overline{i_{n 2}}+\cdots \overline{i_{n x}}\right)}{n}
\end{aligned}
$$

where $\overline{p_{n x}}$ is the mean percentage of stained nuclei of three representative fields of tumor $X, \overline{i_{n X}}$ the mean staining intensity of three representative fields of tumor $X$ and ES the expression score.

\section{Phosphorylated pRb (p-pRb) and Prognosis}

Tissue sections from high-risk nodular melanomas from patients with long-time follow-up information were analyzed concerning the expression of $\mathrm{pRb}$, p-pRb Ser795, p-pRb Ser780 and p-pRb Ser807/811. Five patients with an exceptional long-term survival of more than 5 years despite high tumor thickness (Breslow index $\geq 3.5 \mathrm{~mm}$ ) were selected from 8000 patients in the local database. In addition, eight matched cases with a more typical average survival of 25.3 months (short-time survival) were considered. The cases were matched for tumor thickness, similar location, same sex of patient and age. This cohort is thought as a model for evaluating prognostic factors that are possibly independent of tumor thickness. A more detailed description of this cohort is given in Vogt et al. ${ }^{14}$ For correlation with prognosis, $\mathrm{p}-\mathrm{pRb}$ of all three antibodies were summarized as $\mathrm{p}-\mathrm{pRb}$ index for each individual tumor:

p-pRbindex $=\frac{(\bar{p} \times \bar{i})_{\operatorname{Ser780}}+(\bar{p} \times \bar{i})_{\operatorname{Ser} 795}+(\bar{p} \times \bar{i})_{\operatorname{Ser} 807 / 811}}{3}$

where $\bar{p}$ is the mean percentage of stained nuclei of three representative fields of a tumor, $\bar{i}$ the mean staining intensity of three representative fields of a tumor and p-pRb index the prognostic index.

For this p-pRb index, areas with maximum staining were considered within each section. For subsequent Kaplan-Meier analysis, an empirical threshold of 30.0 was used.

\section{Statistical Analysis}

The SPSS 10.0 (SPSS Inc, Erkrath, Germany) software package was used to perform statistical analyses. For assessment of relative mRNA expression levels the nonparametric Mann-Whitney U-test was applied. For assessment of intratumoral differences of protein expression we used the Wilcoxon test for coupled samples. Kaplan-Meier curves were evaluated by a log-rank test. For all statistical tests a probability of error $P<0.05$ was required.

\section{Results}

\section{Rb mRNA Expression in Melanocytic Tumors and Normal Tissues}

Relative measurements of Rb mRNA expression in microdissected melanocytic tumor biopsies revealed a significant almost threefold overexpression of $\mathrm{Rb}$ mRNA in malignant melanomas $(n=5$, mean 0.45 , range $0.18-0.72$, s.d. $\pm 0.22 ; P<0.05)$ and melanoma metastases $(n=7$, mean 0.44 , range $0.15-0.63$, s.d. $\pm 0.17 ; P<0.01)$ vs benign melanocytic nevi $(n=6$, mean 0.16 , range $0.10-0.21$, s.d. \pm 0.05 ). In contrast, expression levels of various non-neuroectodermalmalignant control tissues (mRNAs from lung carcinoma, breast carcinoma, colon carcinoma) showed uniformly low expression levels. Interestingly, a similar trend of $\mathrm{Rb}$ mRNA overexpression was also detected in glioblastomas, which served as independent controls derived from a different entity of neuroectodermal cancer. In glioblastomas $(n=5)$ the $\mathrm{Rb}$ mRNA expression also exceeded the mRNA levels of normal tissue (fetal and adult brain) twoto threefold (Figure 1).

\section{Immunohistochemical Staining of Total $\mathrm{pRb}$ and Phosphorylated pRb (p-pRb Ser780, Ser795 and Ser807/811) Using Tissue Microarrays}

In accordance with our RT-PCR data, tissue microarray-based immunohistochemistry confirmed gross constitutive differences in the pRb-expression between melanocytic nevi $(n=60)$ and melanoma metastases $(n=60)$ (Figure 2). Interestingly at Ser795, we found an almost complete phosphorylation of the progressively overexpressed total pRb, whereas in melanocytic nevi only a fraction of total $\mathrm{pRb}$ was phosphorylated. Phosphorylation at Ser807/811 generally occurred to a lesser extent, but significantly higher in melanoma metastases compared to melanocytic nevi. In case of Ser780, no significant differential phosphorylation between nevi and metastases was detectable.

\section{Immunohistochemical Staining of Total $p R b$ and p-pRb in Sections with Preserved Tumor Architecture}

In order to analyze possible intratumoral heterogeneity that may be missed by tissue microarrays due to limited punch size, we also analyzed sections 
with preserved full tumor architecture. Expression scoring for total $\mathrm{pRb}$ in complete tumor sections was in support of our RT-PCR results, that is, a pro-

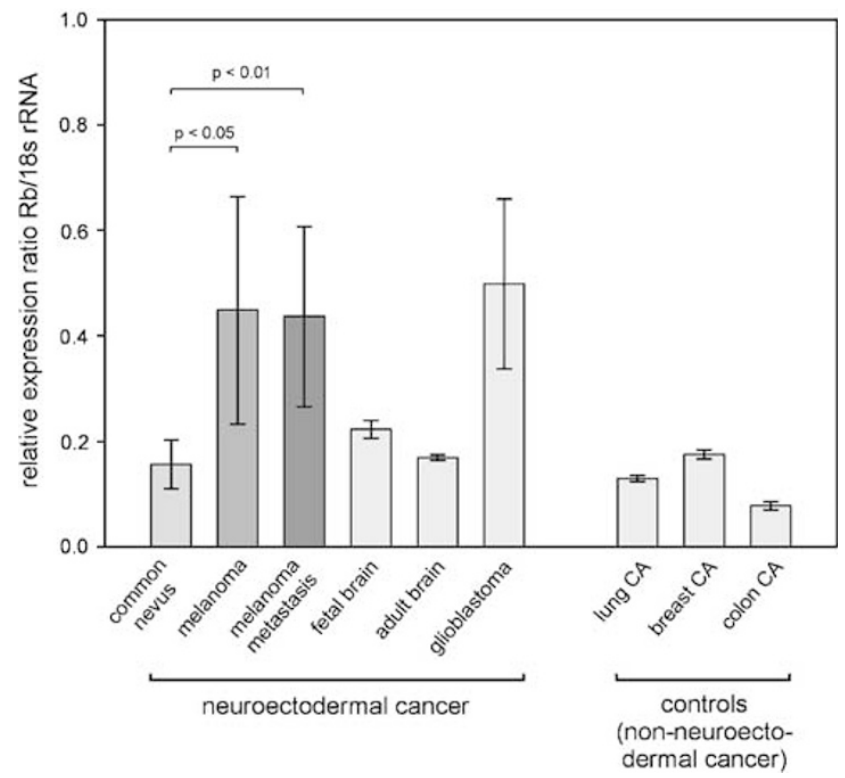

Figure 1 Relative quantitation of $\mathrm{Rb}$ mRNA expression in neuroectodermal tumors revealed an overexpression in malignant melanocytic lesions and glioblastomas compared to benign melanocytic nevi and normal brain tissue. Measurements were performed by real-time PCR. Error bars indicate the standard deviations. gressive increase of $\mathrm{pRb}$ in malignant melanocytic tumors (details are given in Table 1 and Figure 3). Comparing expression scores from complete sections with tissue microarray-based results, the progressive increase in phosphorylation could be confirmed for all three phospho sites analyzed. And, as we have already suggested from the tissue microarrays, Ser795 reached the highest expressions scores in metastases. In primary melanomas both Ser780 and Ser795 were typically phosphorylated. Furthermore, the complete tissue sections did reveal a considerable intratumoral heterogeneity of total $\mathrm{pRb}$ expression. In superficial spreading melanomas, subepidermal vs dermal ES were significantly different with the most intense staining result in the subepidermal-lateral portions $(P<0.005)$. In nodular malignant melanomas, the invasive part vs tumor center $(P<0.001)$ and in melanoma metastases outer margins vs centers $(P<0.003)$ also showed significant differences (Table 1). Other benign neuroectodermal tumors that served as independent controls such as schwannomas and neurofibromas showed a comparably low 'melanocytic nevus-like' pRbexpression with no significant intratumoral heterogeneity (not shown). Accordingly, p-pRb typically showed a subepidermal-lateral maximum of staining scores in superficial spreading melanomas (Figure $3 \mathrm{~g}-\mathrm{i}$ ) and in deep-dermal invading protrusions of nodular malignant melanomas (Figure 3j-l). In melanoma metastases, an accumulation of $\mathrm{p}-\mathrm{pRb}$ staining was mainly detected in the outer margins

\section{total $\mathrm{pRb}$}

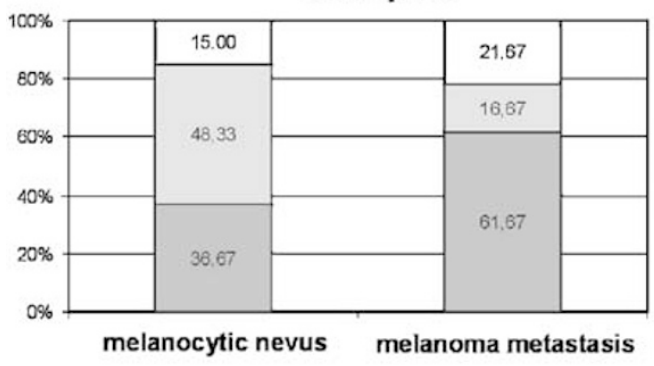

\section{p-pRb Ser795}

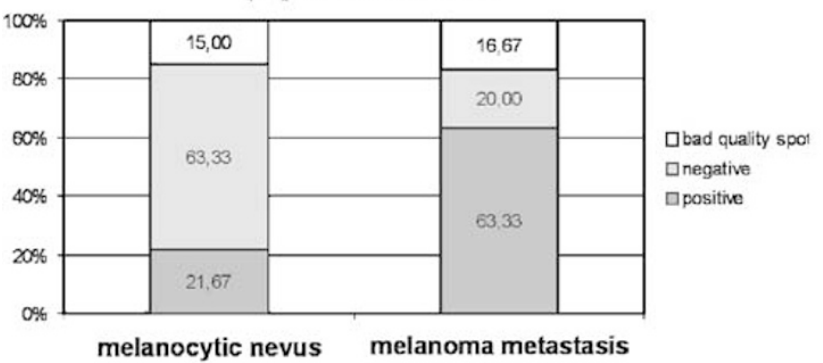

\section{p-pRb Ser780}

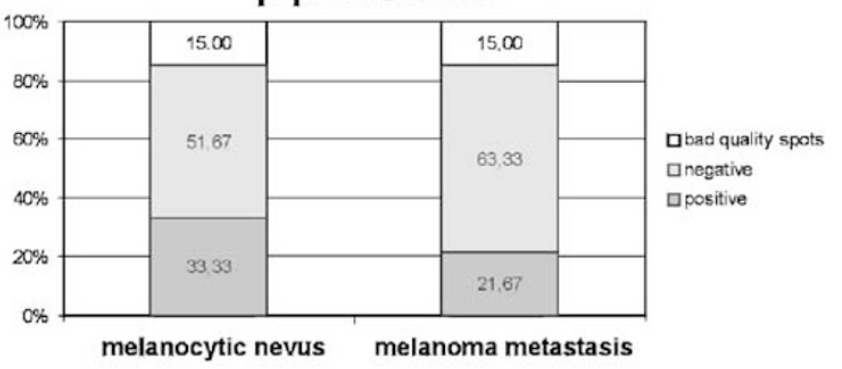

p-pRb Ser807/811

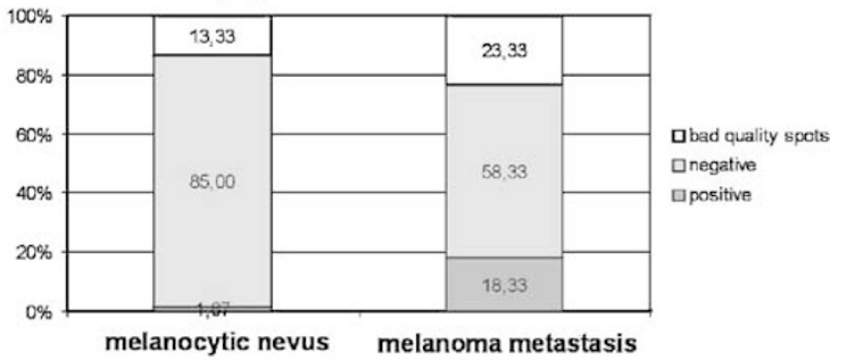

Figure 2 Tissue microarray-based evaluation of total pRb- and phosphorylated pRb (p-pRb) Ser795/Ser780/Ser807/811-expression in 60 melanocytic nevi vs 60 melanoma metastases. Depicted are percentages of positive ( $>10 \%$ of the nuclei stained) and negative samples $(<10 \%$ of the nuclei stained) as well as bad quality spots. At Ser795, an almost complete phosphorylation of the progressively overexpressed total $\mathrm{pRb}$ is found. Phosphorylation at Ser807/811 occurred to a lesser extent, but significantly higher in melanoma metastases compared to melanocytic nevi. In case of Ser780, no significant differential phosphorylation between nevi and metastases was detectable. 
Table $1 \mathrm{pRb}$ - and p-pRb expression in tumors with neuroectodermal origin

\begin{tabular}{lc}
\hline & Expression score \\
\cline { 2 - 2 } & $E S_{\max }$ \\
\hline Melanocytic nevus & $E S_{\min }$ \\
Total pRb & Homogenous staining \\
p-Rb 807/811 & $167.1 \Rightarrow++$ \\
p-Rb 780 & $52.2 \Rightarrow+$ \\
p-Rb 795 & $98.5 \Rightarrow+$ \\
\hline
\end{tabular}

\begin{tabular}{lcc}
\hline Dysplastic nevus & \multicolumn{2}{c}{ Almost homogenous staining } \\
\cline { 2 - 3 } & Subepidermal & Dermal \\
Total pRb & $262.7 \Rightarrow+++$ & $213.9 \Rightarrow+++$ \\
p-Rb 807/811 & $24.8 \Rightarrow+$ & $20.1 \Rightarrow+$ \\
p-Rb 780 & $72.4 \Rightarrow+$ & $60.5 \Rightarrow+$ \\
p-Rb 795 & $56.3 \Rightarrow+$ & $60.0 \Rightarrow+$ \\
\hline
\end{tabular}

Superficial spreading melanoma Heterogeneous staining

\begin{tabular}{lcc}
\cline { 2 - 3 } & Subepidermal & Dermal \\
Total pRb & $260.9 \Rightarrow+++$ & $164.3 \Rightarrow++$ \\
p-Rb 807/811 & $42.3 \Rightarrow+$ & $29.8 \Rightarrow+$ \\
p-Rb 780 & $111.6 \Rightarrow++$ & $94.1 \Rightarrow+$ \\
p-Rb 795 & $87.6 \Rightarrow+$ & $84.9 \Rightarrow+$ \\
\hline
\end{tabular}

Nodular malignant melanoma

Heterogeneous staining

\begin{tabular}{|c|c|c|}
\hline Total pRb & $264.3 \Rightarrow+++$ & $167.3 \Rightarrow++$ \\
\hline p-Rb 807/811 & $61.9 \Rightarrow+$ & $64.7 \Rightarrow+$ \\
\hline p-Rb 780 & $132.9 \Rightarrow++$ & $76.1 \Rightarrow+$ \\
\hline p-Rb 795 & $100.8 \Rightarrow++$ & $49.6 \Rightarrow+$ \\
\hline
\end{tabular}

Melanoma metastasis

Heterogeneous staining

Total pRb

p-Rb 807/811

p-Rb 780

p-Rb 795

Outer margin Tumor center

$400.0 \Rightarrow++++\quad 268.3 \Rightarrow+++$

$112.1 \Rightarrow++\quad 61.4 \Rightarrow+$

$250.8 \Rightarrow+++\quad 124.2 \Rightarrow++$

$265.0 \Rightarrow++\quad 148.7 \Rightarrow++$

Schwannoma

Homogenous staining

Total pRb

p-Rb 807/811

p-Rb 780

p-Rb 795

$370.6 \Rightarrow++++$

$25.2 \Rightarrow+$

$50.4 \Rightarrow+$

$31.3 \Rightarrow+$

Neurofibroma

Homogenous staining

Total pRb

$\mathrm{p}-\mathrm{Rb} 807 / 811$

p-Rb 780

p-Rb 795

$$
\begin{aligned}
108.8 & \Rightarrow++ \\
0 & \Rightarrow \varnothing \\
38.4 & \Rightarrow+ \\
38.3 & \Rightarrow+
\end{aligned}
$$

The averaged expression values were ranked in staining classes from $\varnothing$ to ++++. Due to homogenous intralesional staining patterns in melanocytic nevi, schwannomas and neurofibromas, discrimination between strongly and weakly stained areas was not applicable. For higher clearness, the averaged expression values were ranked in staining classes: EV $0=\varnothing,>0-\leq 100 \%=+,>100-\leq 200 \%=++$, $>200-\leq 300 \%=+++,>300=++++$. compared to the tumor center. In contrast, in benign and dysplastic nevi as well as schwannomas/ neurofibromas $\mathrm{pRb}$ phosphorylation was almost negligible (Table 1).

\section{pRb Phosphorylation and Prognosis}

We found a clear trend to higher p-pRb indices in short-time survivors vs exceptional long-time survivors in our cohort of matched survivors and nonsurvivors with high Breslow-indices (tumor thickness $>3.5 \mathrm{~mm}$ ) (Table 2, Figure 4). Using an arbitrary threshold of 30.0 as discriminating factor in Kaplan-Meier statistics, low $\mathrm{p}$-pRb indices $(<30.0)$ were significantly correlated with a prolonged survival, whereas high $\mathrm{p}-\mathrm{pRb}$ indices $(>30.0)$ were correlated with early death (log-ranktest $P=0.03$ ). This suggests a possible Breslow(tumor thickness)-independent prognostic impact of pRb-phosphorylation.

\section{Discussion}

In this study, we can confirm for the first time by two independent methods, real-time RT-PCR and immunohistochemistry, that (i) in cutaneous malignant melanocytic tumors total Rb-expression is progressively upregulated and that (ii), simultaneously, augmented total $\mathrm{pRb}$ is probably functionally inactive due to protein hyperphosphorylation. Interestingly, a particularly high degree of $p R b$ phosphorylation can be observed in tumor regions with expansive growth activity, that is, the deep invasive front of the vertical growth phase of nodular melanomas and the lateral-subepidermal parts of superficial spreading melanomas. Accordingly, the benign counterparts analyzed (melanocytic nevi, schwannomas, neurofibromas) show a moderate, mostly homogeneous expression of $\mathrm{pRb}$ and pRb-phosphorylation.

Concerning $\mathrm{pRb}$ expression in malignant melanomas, partly conjectural data have been reported in the past. Korabiowska et $a l^{15}$ postulated a downregulation of total $\mathrm{pRb}$ during melanoma progression. In contrast, Maelandsmo et $a l^{16}$ and Saenz-Santamaria et $a l^{17}$ reported about a significant upregulation of $\mathrm{pRb}$ in primary and metastatic melanomas. Based on latter findings, it was suggested that $\mathrm{pRb}$-mutations or a lack of expression probably play a subordinate role in melanoma. It was further speculated that the reduction of pRb-activity due to hyperphosphorylation could be a causal principle of unlimited growth of melanoma. ${ }^{3,4}$

To the best of our knowledge, this is the first report on $\mathrm{p}$-pRb in in vivo samples of cutaneous malignant melanomas. Employing currently available phosphorylation site-directed antibodies, we have analyzed three out of 16 possible phosphorylation sites of $\mathrm{pRb}$. p-pRb Ser795 showed the best 
correlation with total amounts of $\mathrm{pRb}$ in the tissue microarrays and the highest expression scores in complete tumor sections of melanoma metastases.
This suggests that p-pRb Ser795 is a good choice for estimating both the presence of $\mathrm{pRb}$ and its degree of inactivation. Specifically, Ser795 is among those
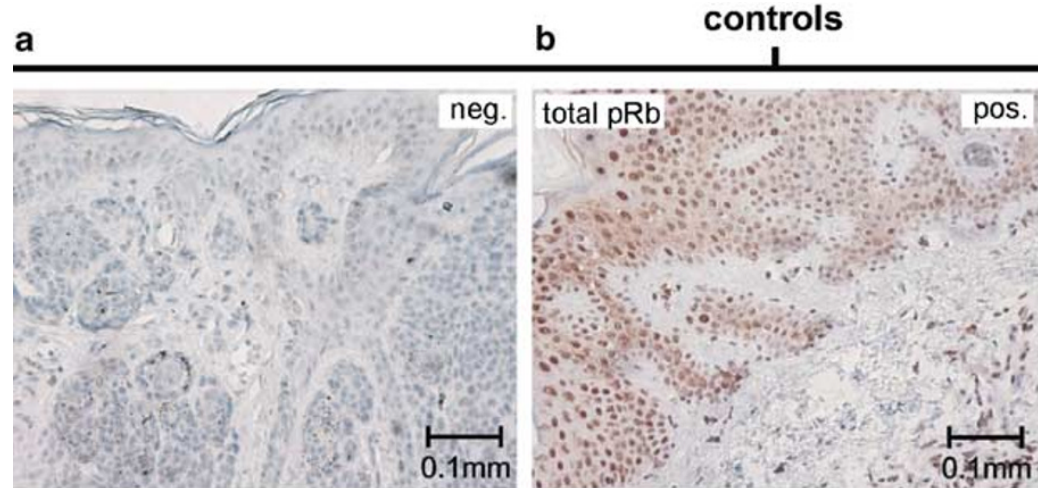

C
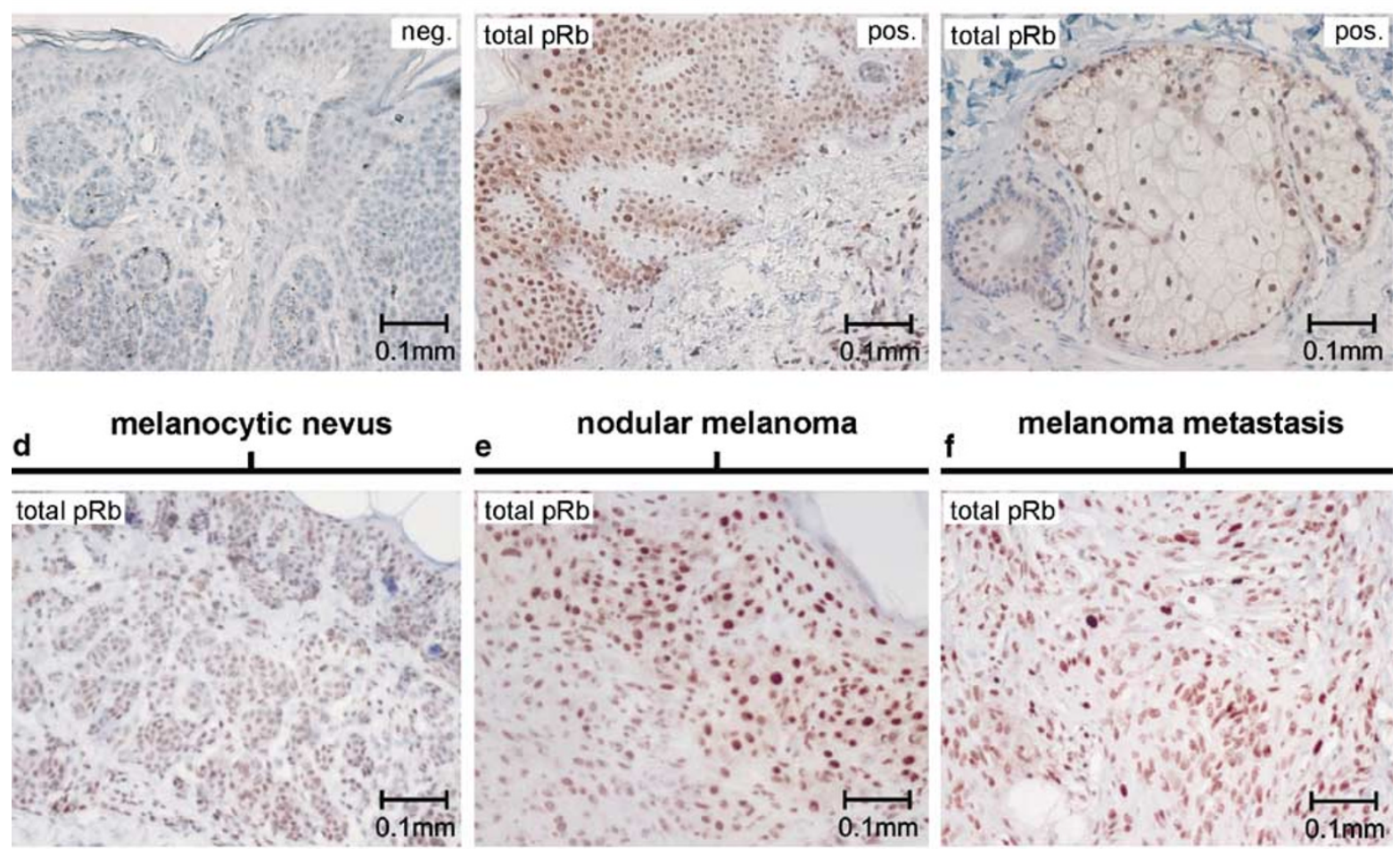

\section{superficial spreading melanoma}

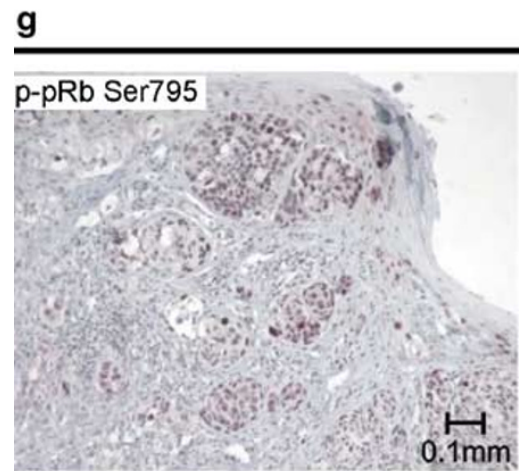

h
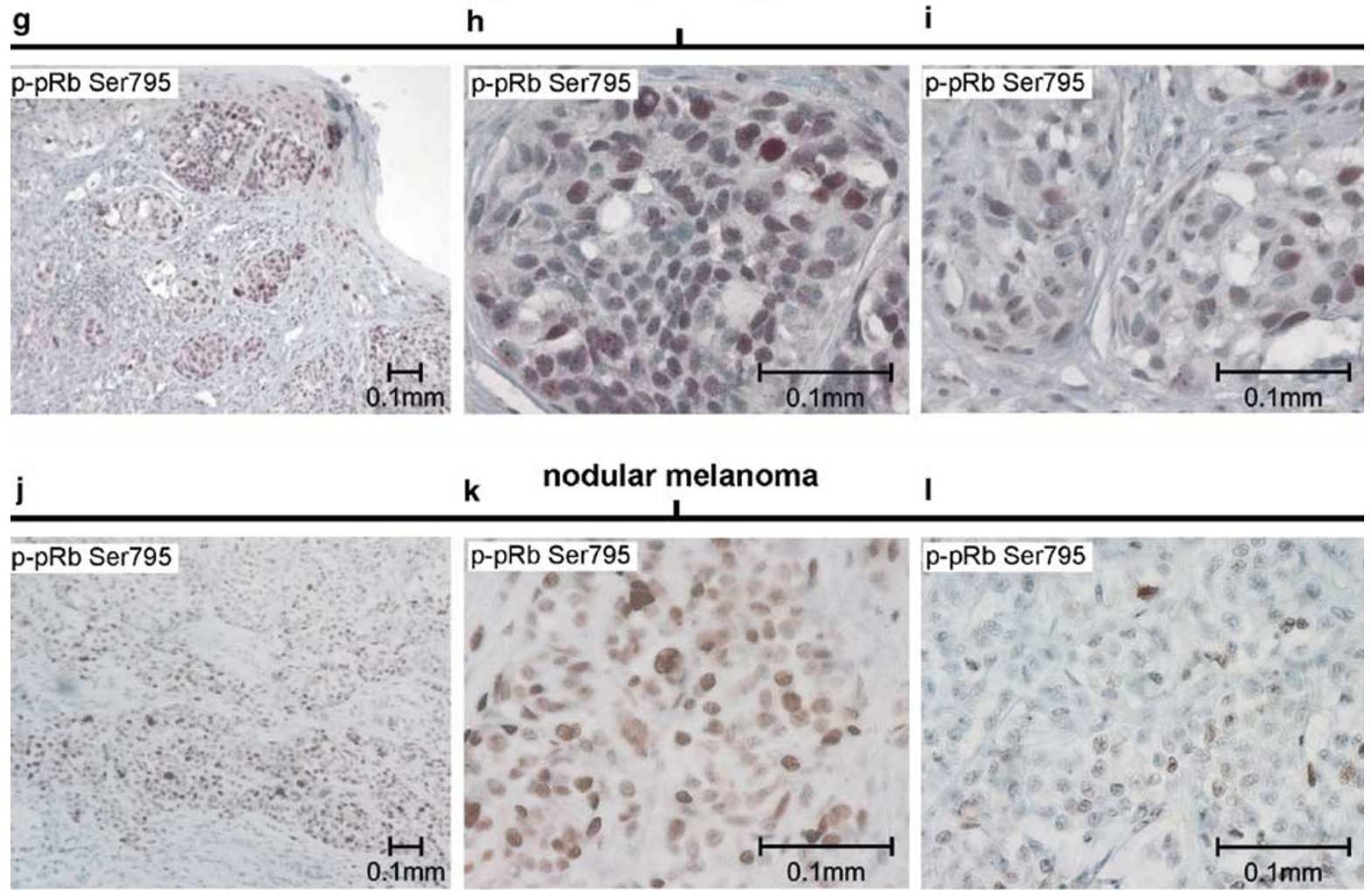
Table $2 \mathrm{p}$-pRb indices of MM cases with high Breslow indices (tumor thickness) and long-time follow-up

\begin{tabular}{lcclr}
\hline $\begin{array}{l}\text { Patient } \\
\text { initials }\end{array}$ & $\begin{array}{c}\text { Tumor } \\
\text { thickness } \\
(\mathrm{mm})\end{array}$ & $\begin{array}{c}\text { Follow-up } \\
\text { time (months) }\end{array}$ & $\begin{array}{l}\text { Life status at the } \\
\text { time of analysis }\end{array}$ & $\begin{array}{c}p-p R b \\
\text { index }\end{array}$ \\
\hline HO & 3.6 & 111 & Alive & 25 \\
SC & 5.5 & 111 & Alive & 27 \\
RH & 3.8 & 62 & Alive & 108 \\
WE & 4.8 & 93 & Alive & 28 \\
RG & 3.8 & 72 & Alive & 110 \\
RE & 5.2 & 27 & Deceased & 172 \\
ED & 8.0 & 43 & Deceased & 47 \\
WI & 3.5 & 19 & Deceased & 50 \\
KN & 4.0 & 20 & Deceased & 83 \\
ST & 5.7 & 31 & Deceased & 86 \\
HE & 3.6 & 28 & Deceased & 36 \\
HA & 3.5 & 17 & Deceased & 40 \\
KA & 4.9 & 17 & Deceased & $22^{\text {a }}$ \\
\hline
\end{tabular}

${ }^{\mathrm{a}} \mathrm{p}-\mathrm{pRb}$ Ser795 staining failed.

phosphorylation sites that undergo hyperphosphorylation by CDK2-E in late G1. This results in the release of E2F that finally leads to an enhanced transcription of S-phase genes such as DNA polymerase $\alpha$ and dihydrofolate reductase. ${ }^{1,18-21}$ In contrast to Ser795, Ser780 and Ser807/811 are exclusively phosphorylated by CDK4-D..1,19,20,22 Interestingly Ezhevsky et $a l^{23}$ reported that CDK4-D-mediated phosphorylation of $\mathrm{pRb}$ is a prerequisite for the transition of unphosphorylated inactive $\mathrm{pRb}$ into hypophosphorylated active $\mathrm{pRb}$. This suggests that the increase in pRb phosphorylation at Ser780 detected in benign nevi represents active cell cycling suppressing $\mathrm{pRb}$. Therefore, it could be worthwhile to further unravel the details of the phosphorylation status of all pRb phosphorylation sites in melanoma. However, currently the usefulness and practical value of a diversified analysis of all phosphorylation residues of $\mathrm{pRb}$ remains elusive due to limited availability of suitable antibodies. Nevertheless, the status of the three phosphorylation sites analyzed seems to harbor potentially prognostic information, possibly independent of tumor thickness. To date, tumor thickness is considered as the most valid prognostic factor in melanomas and within certain limits an almost linear correlation between tumor thickness and metastatic risk has been demonstrated. ${ }^{24}$

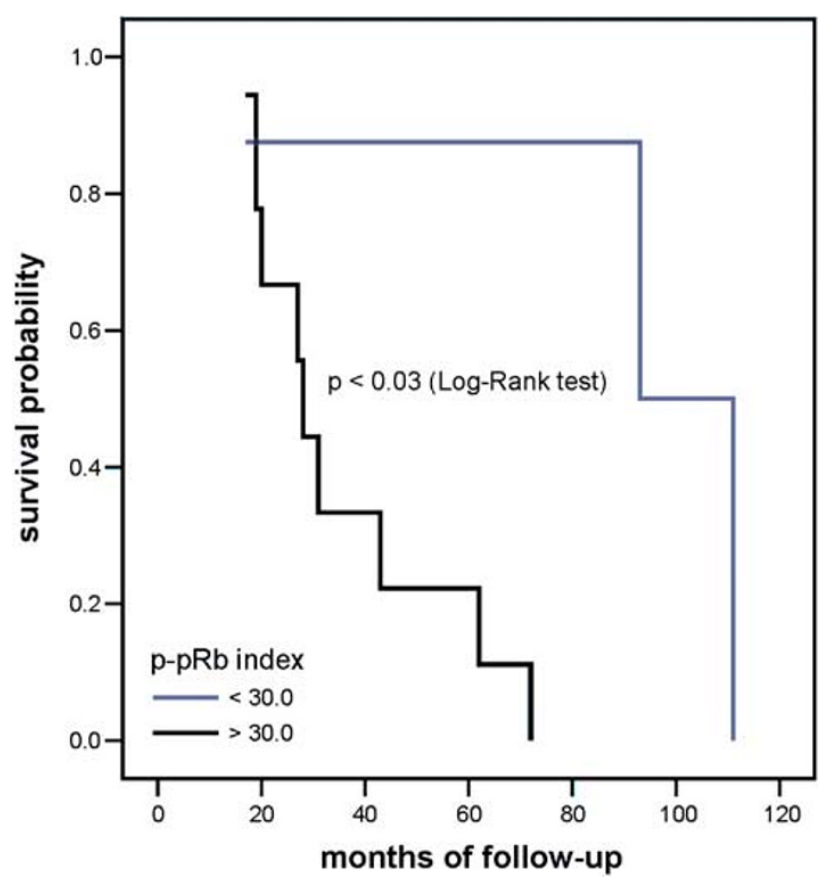

Figure 4 Kaplan-Meier survival curves of 13 high-risk nodular melanomas (tumor thickness $>3.5 \mathrm{~mm}$ ) with long-time follow-up. The prognostic $p-p R b$ index was set up on the basis of $p-p R b$ Ser780/795/807/811 staining in tissue sections with preserved tumor architecture (see Materials and methods). Using an arbitrary threshold of 30.0, low p-pRb indices $(<30.0)$ were significantly correlated with a prolonged survival, whereas high $\mathrm{p}$-pRb indices $(>30.0)$ were correlated with early death (log-ranktest $P=0.0314$ )

However, recent studies on several thousands of patients ${ }^{24}$ also delineate limitations of tumor thickness used as single predictor. In particular, if the tumor thickness exceeds $3.5 \mathrm{~mm}$, it loses predictive power. $^{25}$

We conclude that in neuroectoderm-derived cancers, melanocytic tumors and glioblastomas, overexpression of the cell cycle controller $\mathrm{pRb}$ is limited to the malignant phenotype. pRb is markedly overexpressed in actively growing parts of malignant melanomas and coincident with hyperphosphorylation and possible $p R b$ inactivation. Since $p-p R b$ content seems correlated with prognosis, evaluation of p-pRb status in melanocytic tumors could, therefore, become a helpful adjunct in clinicopathological routine.

Figure 3 Staining patterns of total $\mathrm{pRb}$ and $\mathrm{pRb}$ phosphorylated at Ser795 $(\mathrm{p}-\mathrm{pRb}$ Ser795) in melanocytic tumors. First row $(\times 200$ magnification): (a) Negative control with isotype matched antibodies, (b, c) positive controls (stratum germinativum of the epidermis and sebaceous gland). Second row ( $\times 200$ magnification): Increasing total pRb expression with rising malignancy: (d) benign melanocytic nevus, (e) nodular malignant melanoma and (f) melanoma metastasis. Third row: p-pRb-staining of a superficial spreading melanoma. (g) Overview ( $\times 100$ magnification) showing a high regional variance of $p$-pRb staining with a maximum in subepidermal-lateral nests $v s$ dermal melanoma nests. (h) $\times 400$ magnification of a highly phosphorylated subepidermal melanoma nest in comparison to dermal nests (i). Fourth row: p-pRb-stained nodular melanoma. (j) Overview ( $\times 100$ magnification) showing an increase of pRb-phosphorylation in the invasive basal front. (k) $\times 400$ magnification of the invasive front and almost complete absence of $\mathrm{p}$-pRb in central tumor areas $(\mathbf{l})$. 


\section{References}

1 Kaelin Jr WG. Recent insights into the functions of the retinoblastoma susceptibility gene product. Cancer Invest 1997;15:243-254.

2 Ho A, Dowdy SF. Regulation of G(1) cell-cycle progression by oncogenes and tumor suppressor genes. Curr Opin Genet Dev 2002;12:47-52.

3 Bartkova J, Lukas J, Guldberg P, et al. The p16-cyclin D/ Cdk4-pRb pathway as a functional unit frequently altered in melanoma pathogenesis. Cancer Res 1996; 56:5475-5483.

4 Halaban R, Miglarese MR, Smicun Y, et al. Melanomas, from the cell cycle point of view (Review). Int J Mol Med 1998;1:419-425.

5 Czajkowski R, Drewa T, Wozniak A, et al. Cell cycle in sporadic melanoma. Int J Dermatol 2002;41: 550-556.

6 Halaban R, Cheng E, Smicun Y, et al. Deregulated E2F transcriptional activity in autonomously growing melanoma cells. J Exp Med 2000;191:1005-1016.

7 Halaban R. Melanoma cell autonomous growth: the $\mathrm{Rb} / \mathrm{E} 2 \mathrm{~F}$ pathway. Cancer Metast Rev 1999;18: 333-343.

8 Brantley Jr MA, Harbour JW. Deregulation of the $\mathrm{Rb}$ and p53 pathways in uveal melanoma. Am J Pathol 2000;157:1795-1801.

9 Brantley Jr MA, Harbour JW. Inactivation of retinoblastoma protein in uveal melanoma by phosphorylation of sites in the $\mathrm{COOH}$-terminal region. Cancer Res 2000;60:4320-4323.

10 Hafner C, Bataille F, Meyer S, et al. Loss of EphB6 expression in metastatic melanoma. Int J Oncol 2003; 23:1553-1559.

11 Hafner C, Schmitz G, Meyer S, et al. Differential gene expression of Eph receptors and ephrins in benign human tissues and cancers. Clin Chem 2004;50: 490-499.

12 Rumpler G, Becker B, Hafner C, et al. Identification of differentially expressed genes in models of melanoma progression by cDNA array analysis: SPARC, MIF and a novel cathepsin protease characterize aggressive phenotypes. Exp Dermatol 2003;12:761-771.

13 Kononen J, Bubendorf L, Kallioniemi A, et al. Tissue microarrays for high-throughput molecular profiling of tumor specimens. Nat Med 1998;4:844-847.
14 Vogt T, Zipperer KH, Vogt A, et al. p53-protein and Ki67-antigen expression are both reliable biomarkers of prognosis in thick stage I nodular melanomas of the skin. Histopathology 1997;30:57-63.

15 Korabiowska M, Ruschenburg I, Betke H, et al. Downregulation of the retinoblastoma gene expression in the progression of malignant melanoma. Pathobiology 2001;69:274-280.

16 Maelandsmo GM, Florenes VA, Hovig E, et al. Involvement of the $\mathrm{pRb} / \mathrm{p} 16 / \mathrm{cdk} 4 /$ cyclin $\mathrm{D} 1$ pathway in the tumorigenesis of sporadic malignant melanomas. Br J Cancer 1996;73:909-916.

17 Saenz-Santamaria MC, McNutt NS, Shea CR. Immunohistochemical expression of retinoblastoma protein in cutaneous melanomas. Br J Dermatol 1995;133: 890-895.

18 Gius DR, Ezhevsky SA, Becker-Hapak M, et al. Transduced p16INK4a peptides inhibit hypophosphorylation of the retinoblastoma protein and cell cycle progression prior to activation of Cdk2 complexes in late G1. Cancer Res 1999;59:2577-2580.

19 Knudsen ES, Wang JY. Differential regulation of retinoblastoma protein function by specific Cdk phosphorylation sites. J Biol Chem 1996;271:8313-8320.

20 Zarkowska T, Mittnacht S. Differential phosphorylation of the retinoblastoma protein by G1/S cyclindependent kinases. J Biol Chem 1997;272:1273812746.

21 Taya Y. RB kinases and RB-binding proteins: new points of view. Trends Biochem Sci 1997;22:14-17.

22 Kitagawa M, Higashi H, Jung HK, et al. The consensus motif for phosphorylation by cyclin D1-Cdk4 is different from that for phosphorylation by cyclin A/E-Cdk2. EMBO J 1996;15:7060-7069.

23 Ezhevsky SA, Nagahara H, Vocero-Akbani AM, et al. Hypo-phosphorylation of the retinoblastoma protein (pRb) by cyclin D:Cdk4/6 complexes results in active pRb. Proc Natl Acad Sci USA 1997;94:10699-10704.

24 Balch CM, Buzaid AC, Soong SJ, et al. Final version of the American Joint Committee on Cancer staging system for cutaneous melanoma. J Clin Oncol 2001;19: 3635-3648.

25 Buttner P, Garbe C, Bertz J, et al. Primary cutaneous melanoma. Optimized cutoff points of tumor thickness and importance of Clark's level for prognostic classification. Cancer 1995;75:2499-2506. 